\title{
$\begin{array}{r}\text { WAGENINGEN } \\ \hline\end{array}$
}

\section{Quantitative land evaluation implemented in Dutch water management}

Hack-ten Broeke, M. J. D., Mulder, H. M., Bartholomeus, R. P., van Dam, J. C., Holshof, G., Hoving, I. E., ... Ruijtenberg, R.

This is a "Post-Print" accepted manuscript, which has been published in "Geoderma"

This version is distributed under a non-commercial no derivatives Creative Commons (c) $(1) \Theta($ (CC-BY-NC-ND) user license, which permits use, distribution, and reproduction in any medium, provided the original work is properly cited and not used for commercial purposes. Further, the restriction applies that if you remix, transform, or build upon the material, you may not distribute the modified material.

Please cite this publication as follows:

Hack-ten Broeke, M. J. D., Mulder, H. M., Bartholomeus, R. P., van Dam, J. C., Holshof, G., Hoving, I. E., ... Ruijtenberg, R. (2018). Quantitative land evaluation implemented in Dutch water management. Geoderma. DOI:

10.1016/j.geoderma.2018.11.002

You can download the published version at:

https://doi.org/10.1016/j.geoderma.2018.11.002 


\section{Quantitative land evaluation implemented in Dutch water management}

3

4 M.J.D. Hack-ten Broeke ${ }^{1}$, H.M. Mulder ${ }^{1}$, R.P. Bartholomeus ${ }^{2,3}$, J.C. van Dam ${ }^{3}$, G. Holshof ${ }^{4}$, 5 I.E. Hoving ${ }^{4}$, D.J.J. Walvoort ${ }^{1}$, M. Heinen ${ }^{1}$, J.G. Kroes ${ }^{1}$, P.J.T. van Bakel ${ }^{5}$, I. Supit ${ }^{1}$, A..J.W.

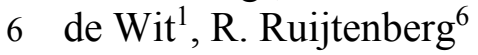
7

$8 \quad{ }^{1}$ Wageningen Environmental Research, Wageningen Research, PO Box 47, 6700 AA Wageningen, the 9 Netherlands

$10 \quad{ }^{2}$ KWR Watercycle Research Institute, PO Box 1072, 3430 BB Nieuwegein, the Netherlands

$11{ }^{3}$ Wageningen University, Soil Physics and Land Management group, PO Box 47, 6700 AA Wageningen, the 12 Netherlands

$13{ }^{4}$ Wageningen Livestock Research, Wageningen Research, PO Box 338, 6700 AH Wageningen, the Netherlands

$14{ }^{5}$ De Bakelse Stroom, Simon Vestdijkstraat 15, 6708 NW Wageningen, the Netherlands

$15{ }^{6}$ STOWA, postbus 2180, 3800 CD Amersfoort, the Netherlands

16

17 Corresponding author: M.J.D. Hack-ten Broeke (mirjam.hack@wur.nl) 


\section{Abstract}

21 Both in land evaluation and in water management quantitative methods, GIS and simulation modelling

22 are well-known techniques for quantifying the effects of changes, such as land use or climate change.

23 For hydrological management decisions information is often required on the effect of those decisions

24 on agricultural production. To serve the needs of different types of users, like water authorities, 25 provinces, drinking water companies and the National Department of Infrastructure and Water

26 Management we developed a toolbox named WaterVision Agriculture as an instrument that can 27 determine effects on crop yield and the farm economy as a result of drought, too wet or too saline 28 conditions for both current and future climatic conditions.

30 WaterVision Agriculture is based on the hydrological simulation model SWAP, the crop growth model

31 WOFOST and farm management and economic assessments such as DairyWise for dairy farming. The

32 WaterVision Agriculture (WVA) project resulted in two products, namely i) an easily applicable tool

33 (also called the WVA-table) and ii) the operational models for hydrology and crop growth SWAP and

34 WOFOST for calculating effects on field scale combined with calculating farm economic results and

35 indirect effects. SWAP simulates water transport in the unsaturated zone using meteorological data,

36 boundary conditions (like groundwater level or drainage) and soil parameters. WOFOST simulates crop

37 growth as a function of meteorological conditions and crop parameters. Using the combination of these

38 process-based models and methods for describing crop management and economic value we derived a

39 meta-model, i.e. a set of easily applicable simplified relations for assessing crop growth as a function of 
40 soil type and groundwater level. These relations are based on multiple model runs for at least 72 soil

41 units and the possible groundwater regimes in the Netherlands. The easily applicable tool (WVA-table)

42 uses this meta-model.

43

44 Applying the meta-model of WaterVision Agriculture should allow for better decisions on land use or

45 soil and water management because the instrument can help to quantify the effects of changes in climate,

46 land use, hydrological conditions or combinations of these effects on agricultural production.

47

48 Keywords: simulation modelling, meta-model, crop yield assessment, soil management, agro-

49

hydrology, land use 
51 Land evaluation can be described as a process for defining the suitability of land for a certain land use.

52 Land evaluation methods have been mostly adopted by soil scientists for predicting potentials of land in

53 the view of changes, such as a new crop rotation, new management practices, changes in water

54 management and in more recent years also climate change. FAO (1976) distinguished two types of land

55 evaluation, namely physical and economic evaluation. Most studies however have focused on physical

56 land evaluation alone. Simulation modelling and Geographical Information Systems (GIS) have greatly

57 enhanced the possibilities for this physical evaluation, often in terms of quantifying crop productivity

58 or specific land qualities (e.g. Bouma and Van Lanen, 1987; Bouma and Bregt, 1989; Hack-ten Broeke

59 et al., 1989; Van Diepen et al., 1991; Van Lanen et al., 1992a; Bouma, 2000; Bonfante and Bouma,

60 2015; Bouma and Wösten, 2016).

61

62 Not only methods based on simulation models and GIS are common land evaluation methods. More

63 qualitative assessments, based on experiments or expert knowledge can also be very useful (Sonneveld

64 et al., 2010). There are various ways to distinguish different land evaluation methods and it is also

65 possible to combine methods, depending on the required results, the relevant scale and on data

66 availability. Van Lanen et al. (1992b,c) successfully combined qualitative and quantitative land

67 evaluation for assessments at the scale of the Netherlands and the European Union.

69 Land evaluation methods are not restricted to soil science related studies. Sonneveld et al. (2010) noticed

70 that "...The application domain of land evaluation procedures has nowadays been broadened from 
71 land use and land allocation to optimum sustainable resource use, and from land use planning to

72 environmental impact assessments and risk assessments, from one-time assessments to continuous

73 monitoring of environmental changes, and to analysis of past trends and future projections, as in scenario

74 studies. It is in this whole new field of interdisciplinary applications that the kind of interpretation

75 procedures as developed originally for land evaluation can make a contribution...”.

77 In this paper we focus on a contribution of quantified physical and economic land evaluation for water 78 management in relation to agricultural land use. The system we developed is called WaterVision

79 Agriculture (in Dutch: Waterwijzer Landbouw). A large part of the method was described by Hack-ten 80 Broeke et al. (2016).

82 Rossiter (1996) wrote “...A fundamental challenge facing land evaluation is to prove its relevance to the 83 many pressing land-use problems of our day. Predictions of land performance, no matter how soundly 84 based, are only useful if they will be used by decision makers, including individual land users, groups, 85 or governments, to make better land-use decisions..." and "...Land evaluators should also accept that not 86 only professional land-use planners have relevant questions, and that not only soil scientists and 87 agronomists have relevant knowledge...” In a reaction Bouma (1996) adds the following: “...In addition, 88 our clients have changed, simulation models and expert systems have been developed, and we have 89 learned that yield alone is certainly not a measure for "suitability", but that the soil system should 90 function harmoniously in wider agro-ecosystems to have a fair chance of being sustainable. And what 91 about the term "suitability" in this context? In my experience, there is an increasing number of users 
92 who are not primarily interested in our judgment about suitabilities of a piece of land for a given Land

93 Use System (LUS). Rather, they want us to give them different realistic options for land use for a given

94 piece of land, with proper technical coefficients...”

96 In water management quantitative methods, GIS and simulation modelling are well-known techniques

97 to produce different realistic options for current and future conditions. For hydrological management

98 decisions information is often required on the effect of those decisions on agricultural production. Land

99 evaluation methods can be very useful for this purpose. To serve the needs of different types of users,

100 like water authorities, provinces, drinking water companies and the National Department of

101 Infrastructure and Water Management we developed a tool named WaterVision Agriculture as an

102 instrument that can determine crop yield effects and the effects on farm economy as a result of drought,

103 too wet or too saline conditions for both current and future climatic conditions based on simulation

104 modelling. In that sense WaterVision Agriculture can be considered as a quantitative physical land

105 evaluation method combined with an economic assessment. The WaterVision Agriculture project

106 resulted in two products, namely i) an easily applicable tool for quantifying effects of too dry, too wet

107 or too saline conditions for current and future climate (also called the WVA-table) and ii) the operational

108 modelsfor hydrology and crop growth SWAP-WOFOST for calculating effects on field scale combined

109 with calculating farm economic results and indirect effects.

111 In this paper the recent developments of WaterVision Agriculture are described as well as the models

112 on which the instrument is based. We show examples of using this instrument for assessments of 
113 hydrological and climate change effects on agriculture for different crops, soil types and groundwater

114 regimes. The examples will show how quantitative physical and economic land evaluation methods are

115 helpful for decision making towards soil and water management for current and future climate.

116 


\section{2. Materials and methods}

118 In WaterVision Agriculture the agrohydrological simulation model SWAP (van Dam et al., 2008; Kroes

119 et al, 2017) and the crop growth simulation model WOFOST (van Diepen et al., 1989) together form

120 the core of the process-based calculation of crop yields as a function of soil moisture conditions. We

121 have linked these models on a daily basis to ensure realistic interaction between water in the root zone

122 and crop growth. For instance: dynamic root growth as a function of weather and soil conditions instead

123 of assuming a static rooting depth will influence water uptake and yield reduction, caused by drought or

124 oxygen stress. This will reduce leaf area and this in turn will reduce transpiration in a more realistic way

125 than assuming average annual crop development. Furthermore the linkage of these models (SWAP-

126 WOFOST) enables us to assess the effects of future climate on the interaction between hydrology and

127 crop growth, as it accounts for the interacting processes in the soil-water-plant-atmosphere system. For

128 economic assessments for dairy farming we linked the system DairyWise (in Dutch: BBPR; Schils et

129 al., 2007) to SWAP-WOFOST. DairyWise simulates grassland management and farm scale economics

130 for dairy farms with different conditions in terms of for instance land and cattle. For arable crops and

131 vegetables we use current prices for calculating economic effects of yield differences.

133 Based on these models we have arrived at an easily applicable land evaluation method with direct

134 relationships between groundwater characteristics and crop yield. For this we have derived a meta-

135 model, which mimics the relevant processes involved and generates roughly the same model results as

136 the SWAP-WOFOST model would do, using much less input data (Hack-ten Broeke et al, 2016). 


\subsection{SWAP}

139 The SWAP (Soil-Water-Atmosphere-Plant; Van Dam et al., 2008; Kroes et al., 2017) model is the

140 hydrological core of WaterVision Agriculture. The model simulates water flow in relation to weather

141 conditions in the unsaturated and saturated upper part of the soil profile, where the interaction between

142 groundwater and surface water is important. The model SWAP calculates the water transport, dissolved

143 substances and soil temperature (Fig. 1).

144 Water transport simulation is based on the Richards equation with a variable sink term for root water

145 extraction. The potential transpiration rate depends on atmospheric conditions (air temperature, wind

146 speed, solar radiation and air humidity) and plant characteristics (reflection coefficient, stomatal

147 resistance, plant height and leaf area index). The potential root water extraction rate at a certain depth,

$148 S_{\mathrm{p}}(z)\left(\mathrm{d}^{-1}\right)$, is considered to be proportional to the root length density and the potential transpiration rate:

$$
S_{\mathrm{p}}(z)=\frac{L_{\text {root }}(z)}{\int_{-D_{\text {root }}}^{0} L_{\text {root }}(z) \mathrm{d} z} T_{\mathrm{p}}
$$

150 with $L_{\text {root }}$ the root length density $\left(\mathrm{cm}^{-2}\right)$ and $D_{\text {root }}$ the root layer thickness $(\mathrm{cm})$.

152 Stresses due to dry or wet conditions and/or high salinity concentrations may reduce $S_{\mathrm{p}}(z)$. The drought

153 stress in SWAP is described by the dry part of the reduction function proposed by Feddes et al. (1978),

154 which is depicted in Fig. 2a. In the moderate pressure head range $h>h_{3}$ root water uptake is optimal.

155 Below $h_{3}$ root water uptake linearly declines due to drought until zero at $h_{4}$ (wilting point). The critical

156 pressure head $h_{3}$ increases for higher potential transpiration rates of $T_{\mathrm{p}}$. 
158 Oxygen stress, defined as daily respiration reduction (i.e. potential minus actual respiration) is calculated

159 with the process-based method of Bartholomeus et al. (2008) for oxygen transport and consumption,

160 which uses generally applied physiological and physical relationships to calculate both the oxygen

161 demand of and the oxygen supply to plant roots (Fig. 3). Oxygen stress occurs when the actual root

162 respiration is lower than the potential root respiration, i.e. when the oxygen supply cannot meet the

163 oxygen demand of plant roots. Root respiration is determined by interacting respiratory (i.e. oxygen

164 consuming) and diffusive (i.e. oxygen providing) processes in and to the soil. The method of

165 Bartholomeus et al. (2008) is applied to all soil layers of SWAP, to account for layer-specific soil

166 physical properties, moisture contents and temperatures.

167

168 SWAP uses the response function of Maas and Hoffman (1977) for salinity stress (Fig. 2b). Below the

169 critical concentration of $E C_{\max }(\mathrm{dS} / \mathrm{m})$ no salinity stress is assumed. At salinity levels above $E C_{\max }$ the

170 root water uptake declines with a constant slope of $E C_{\text {slope }}(\mathrm{m} / \mathrm{dS})$. The actual root water flux, $S_{\mathrm{a}}(z)\left(\mathrm{d}^{-1}\right)$

171 is derived in SWAP by multiplication of the stress factors due to drought, oxygen and salt stress:

$$
S_{\mathrm{a}}(z)=\alpha_{\mathrm{d}}(z) \alpha_{\mathrm{o}}(z) \alpha_{\mathrm{s}}(z) S_{\mathrm{p}}(z)
$$

173 where $\alpha_{\mathrm{d}}(-), \alpha_{\mathrm{o}}(-)$ and $\alpha_{\mathrm{s}}(-)$ are reduction factors due to drought, oxygen and salinity stress, respectively.

174 Integration of the actual root water flux over the root zone yields the actual transpiration rate $T_{\mathrm{a}}\left(\mathrm{cm} \mathrm{d}^{-}\right.$ $\left.175^{1}\right)$ :

$$
T_{\mathrm{a}}=\int_{-D_{\text {root }}}^{0} S_{\mathrm{a}}(z) \partial z
$$


177 The SWAP user manual and website describe the theoretical background in detail as well as model input

178 and applications (Kroes et al., 2017). SWAP is developed and maintained by Wageningen University

179 and Research centre.

\subsection{WOFOST}

181 The underlying principles of WOFOST have been discussed by Van Keulen and Wolf (1986). The initial

182 version was developed by the Centre for World Food Studies in Wageningen (Van Diepen et al., 1989).

183 The basic processes simulated by WOFOST are phenological development, biomass growth, its

184 partitioning over plant organs, root growth and the soil water balance. The most important external

185 drivers are daily weather data. Other external drivers are initial soil and crop conditions. The most

186 important internal driver is the leaf area index (LAI) which is the result of the leaf area dynamics

187 controlled by photosynthesis, allocation of biomass to leaves, leaf age and development stage. In turn,

188 LAI controls the daily rates of photosynthesis and evapotranspiration.

190 Currently, WOFOST as described by Kroes et al. (2017) and De Wit et al. (2018) is able to simulate

191 potential production as governed by atmospheric conditions and plant characteristics, and limited

192 production due to water, oxygen and/or salinity stress. Figure 4 shows the processes and relations

193 incorporated in WOFOST. The radiation energy absorbed by the canopy is a function of incoming

194 radiation and crop leaf area. Using the absorbed radiation and taking into account photosynthetic leaf

195 characteristics, the potential photosynthesis is calculated. The latter is reduced due to water, oxygen 
196 and/or salinity stress, as quantified by the relative transpiration $\left(T_{\mathrm{a}} / T_{\mathrm{p}}\right)$, and yields the actual

197 photosynthesis.

199 Part of the carbohydrates $\left(\mathrm{CH}_{2} \mathrm{O}\right)$ produced are used to provide energy for the maintenance of the living

200 biomass (maintenance respiration). The remaining carbohydrates are converted into structural matter.

201 In this conversion, some of the weight is lost as growth respiration. The dry matter produced is

202 partitioned among roots, leaves, stems and storage organs, using partitioning factors that are a function

203 of the crop development stage. The amount partitioned to the leaves determines leaf area development

204 and hence the capacity of light interception. This interaction of light interception and leaf area growth

205 is a very important positive feedback in WOFOST. The dry weights of the various plant organs are

206 obtained by integrating their growth rates over time. During the development of the crop, part of the

207 living biomass dies due to senescence.

\section{$209 \quad$ 2.3 DairyWise}

211 The DairyWise model is an empirical model that simulates technical, environmental, and financial

212 processes on a dairy farm (Schils et al., 2007). The central component is the FeedSupply model that

213 balances the herd requirements, as generated by the DairyHerd model, and the supply of home grown

214 feeds, as generated by the crop models for grassland and corn silage. When linked with the simulation

215 models for soil-water-plant-atmosphere interactions within WaterVision Agriculture the crop modelling

216 in DairyWise is replaced by SWAP-WOFOST. The output of the FeedSupply model is used as input for 
217 several technical, environmental, and economic sub-models. The sub-models simulate a range of farm

218 aspects such as nitrogen and phosphorus cycling, energy use, and a financial farm budget. The final

219 output then is a farm plan describing all material and nutrient flows and the consequences on the

220 environment and economy. In the model combination within WaterVision Agriculture, DairyWise is a

221 powerful tool for integrated scenario development, for adding especially grassland management to this

222 land evaluation tool, allowing also the quantification of farm economic results (Knotters et al., 2017).

\subsection{Meta-model}

224 The combined models as described in sections 2.1, 2.2 and 2.3 can be used on field and farm level for

225 analysing specific situations using detailed soil information, crop data, weather data and hydrological

226 data etc. The linked models of WaterVision Agriculture were tested and evaluated using experimental

227 datasets (Hack-ten Broeke et al., 2016; Kroes et al., 2015; Knotters et al, 2017).

229 For regional assessments or land evaluation and water management studies on regional and national 230 scale, we derived a tool based on a meta-model. The definition of a meta-model, also in WaterVision 231 Agriculture (WVA), is a simple model derived from another more complex model. In the case of the 232 linked SWAP-WOFOST model this means that the meta-model of SWAP-WOFOST must be able to 233 simulate crop growth as if it was directly calculated using SWAP-WOFOST. A meta-model thus models 234 the model results from another model (the original model). The linkage with DairyWise for the meta235 model was conducted by adding the specific rules for simulating grassland management and economic 236 assessments to SWAP-WOFOST. 
238 The advantage of having a meta-model is that it requires much less input data than the original model.

239 For SWAP-WOFOST simulations for instance we need a soil profile description with hydraulic

240 characteristics and a large number of crop characteristics. For using the meta-model we only need to

241 know soil type and crop type. This makes the meta-model much easier to use and it speeds up the

242 calculations. Based on the input data like crop characteristics, soil properties and meteorological data

243 and on the output data (crop yields and groundwater characteristics) of the complex process-based model

244 SWAP-WOFOST, simple meta-models have been fitted that relate groundwater characteristics to crop

245 yield and crop damage. These meta-models emulate the relevant processes involved and generate

246 roughly the same model results as the SWAP-WOFOST model would do.

248 The meta-models we use for WaterVision Agriculture are so called random forests (Breiman, 2001).

249 Random forests consist of many (usually several hundreds of) classifications or regression trees (CART-

250 models). In our case, we have grown forests with regression trees. Each regression tree predicts crop

251 growth given a set of explanatory variables like crop type, soil type, meteorological district, climate

252 scenario, and several groundwater characteristics (e.g. mean groundwater level, mean highest

253 groundwater level, mean lowest groundwater level). Starting at the trunk of a regression tree, the data

254 are recursively split into smaller parts based on simple rules like "IF soil type is sandy loam THEN

255 follow the left branch down the tree ELSE follow the right branch down the tree". Each branch of the

256 tree is split in turn until a terminal leaf is reached. This leaf contains a prediction (in our case crop

257 growth). Instead of a single tree, random forests employ an entire ensemble of regression trees (forest 
258 of trees) to improve prediction accuracy by averaging the predictions of all individual regression trees.

259 Each regression tree is constructed given a bootstrap sample of the original data. A bootstrap sample is 260 obtained by sampling the original data with replacement. The size of each bootstrap sample is equal to 261 the size of the original data. See Breiman (2001) for more details about random forests.

263 For deriving the meta-model, the SWAP-WOFOST combination was run for a period of thirty years for 264 each combination of crop (15), soil unit of the Dutch soil physical database (72), weather station (5), 265 climate conditions (2) and lower boundary conditions (100). Lower boundary conditions have been 266 drawn by means of Latin hypercube sampling. This sampling method enforces an efficient coverage of 267 the parameter space. Each run with the SWAP-WOFOST model results in many outputs. Of these 268 outputs, we used 30-year average crop yield and crop damage as response variables, and groundwater 269 characteristics like the mean highest groundwater level and the mean lowest groundwater level as 270 explanatory variables of the meta-model.

272 Meteorological data were available from the Royal Netherlands Meteorological Institute KNMI. This 273 data involves daily global radiation, minimum and maximum temperature, air humidity, wind speed, 274 rainfall amounts and duration for five weather stations in the Netherlands for 30-year periods. KNMI 275 provides current weather data for the period 1981-2010 as well as projected data for 30-year periods 276 around 2050 for different climate scenarios (KNMI, 2014). 
278 Soil profile information was obtained from the BOFEK 2012 data-base (Wösten et al., 2013). It contains

279 soil physical data for 72 representative soil profiles covering the whole of the Netherlands.

281 The meta-model is also known as the WaterVision Agriculture table (WVA-table) and can be applied

282 for quantifying agricultural yield for any given region in the Netherlands on the basis of soil type,

283 groundwater characteristics, weather station and crop type. The WVA-table distinguishes the effects of

284 drought and water excess on yield, directly related to reduced crop transpiration and also the so-called 285 indirect effects.

287 Indirect effects on agricultural yield are the result of for instance a) suboptimal hydrological conditions

288 or cold weather affecting workability or bearing capacity inducing a late start of the growing season or

289 b) late crop emergence as a result of low soil temperature or c) hydrological conditions hindering

290 harvest, mowing or grazing. Reduced crop yield can thus be attributed to direct drought stress or oxygen

291 stress in the root zone or to indirect effects. The occurrence of these indirect effects are simulated along 292 with the other effects with the SWAP-WOFOST model because soil moisture conditions and soil

293 temperature in the root zone are both simulated with the model. For the different management types like

294 sowing or planting and harvesting different crop dependent threshold values for the pressure head in the

295 root zone are used. These define workability and bearing capacity, similar as performed by Bouma and

296 Van Lanen (1987). 
298 In the case of irrigation an extra input parameter is required, namely the salt concentration in irrigation

299 water. This allows the quantification of crop yield reduction by the WVA-table due to salty conditions

300 in the root zone for crops like potato and vegetables.

\subsection{Pilot regions}

303

304 The WVA-table was applied to two regions in the Netherlands (Fig. 5), namely in the south (De Raam)

305 and east (De Vecht) of the country. In both regions most of the soils are sandy (Heinen et al., 2017). In

306 the area De Raam 33 units of the soil physical database BOFEK occur, but $78 \%$ of the area consists of 307 slightly loamy sandy soils (mostly Podzols and Cambisols (IUSS Working Group WRB, 2015)). In the

308 area De Vecht this is similar with 22 units of the BOFEK-database and $83 \%$ of the area consisting of 309 sandy soils.

311 The questions of the water authorities for the pilot application of the WVA-table were different. For De

312 Vecht we focussed on the effect of a potential wetting scheme as well as the potential effect of climate

313 change for the area and for De Raam the water authority was mainly interested in the differences between

314 hydrological years focussing on relatively dry and relatively wet growing seasons. For both regions only

315 grassland and silage maize were evaluated. 


\section{Results}

318 3.1 Examples for application of the meta-model (WVA-table) at regional scale

319 For the area De Raam the 30-year average relative yield is shown in Fig. 6 for both grassland and silage 320 maize. The WVA-table is applied as if the land use of the total area is either only grassland or only 321 silage maize. The grassland was considered to be only used for cutting and not grazing. Especially silage

322 maize seems to encounter suboptimal hydrological conditions according to Fig. 6 . When the effects of 323 drought and oxygen stress are presented separately (also Fig. 6) it is obvious that for silage maize the 324 area De Raam is mostly too wet. This is due to relatively shallow groundwater levels. In the case of 325 grassland suboptimal conditions for agriculture are not very pronounced.

327 In many cases it is not only interesting to know the effect of soil and hydrological conditions in terms 328 of 30-year averages, but also to know what may happen in individual years. In Fig. 7 this is illustrated 329 for the driest and wettest year within the series of simulated 30 years, namely 1996 and 1998 330 respectively. For grassland the results for a dry year show more crop damage than the long term average, 331 but in a wet year grass yield is similar to the long term average. Figure 7 also tells us again that silage 332 maize yield is mostly affected by wet conditions. In a dry year relatively high maize yields are possible.

334 Similar to Fig. 6, but now for an area within the pilot region De Vecht, Figure 8 shows the 30-year 335 average relative yields for grassland and silage maize and also the distinction between drought stress 336 and oxygen stress. Again, the conditions for grassland are quite good and for maize soil and groundwater 
337 conditions are sometimes suboptimal due to relatively shallow groundwater levels. For the river area

338 near De Vecht hydrological measures are proposed that will lead to slightly higher groundwater levels.

339 The effect on agricultural production can be assessed easily by applying the WVA-table. The water

340 authority was also interested to know what could be the effect of climate change. Both effects are shown

341 in Fig. 9. for both grassland and silage maize. Considering the proposed hydrological measures it is

342 obvious that in most parts of the region there is no effect at all. Only near the river in the southern part

343 of the area noticeable effects of these hydrological measures may occur according to the simulations.

344 Especially for silage maize crop yields are expected to be lower due to wetter circumstances in the area

345 close to the river. The results of the WVA-table for the climate scenario WH (KNMI, 2014) show that

346 climate change might have another additional effect. The differences between future and current climate

347 are mainly caused by increased drought stress.

$349 \quad 3.2$ Results for saline conditions

350 Instead of looking at average results for an area as presented in Section 3.1, the model results can also 351 be further analysed for a specific crop and soil type. An example of this is shown in Fig. 10. for potato 352 and the most common sandy soil in the Netherlands. This soil type is a Cambic Podzol (IUSS Working 353 Group WRB, 2015) with a topsoil of 20 to $30 \mathrm{~cm}$ with an organic matter content of 3 to $5 \%$, and a clay 354 content of $3 \%$. The B and BC-horizon (from 20 or 30 to $60 \mathrm{~cm}$ below soil surface) contains 1 to $2 \%$ 355 organic matter and the Cg-horizon ( $60-120 \mathrm{~cm}$ below soil surface) approximately $0.5 \%$. We then focused 356 on two specific groundwater regimes, a relatively wet type and a dry type. The wet type has a 30-year 
average highest groundwater (AHG) level at a depth within $40 \mathrm{~cm}$ below soil surface and a 30-year average lowest groundwater level (ALG) between 80 and $120 \mathrm{~cm}$ below soil surface. The dry type has an AHG between 80 and $140 \mathrm{~cm}$ below soil surface and an ALG deeper than $140 \mathrm{~cm}$. The graph (box plots; Fig. 10) distinguishes indirect effects, drought stress, oxygen stress and salinity stress. The box plots show that wet conditions will result in indirect effects (due to workability problems) and in oxygen stress for the plant and on the other hand that drier conditions will result in yield reduction because of drought stress. When we allow irrigation in the simulation runs with varying salt concentrations Fig. 10 shows that for the dry groundwater regime the drought stress will be a lot less, but now sometimes yield reduction occurs due to saline conditions. The boxplots for the wet groundwater regime are the same for situations with and without irrigation as expected.

\subsection{Results of different grassland management in terms of economic effects}

The results in section 3.1 and 3.2 are given in terms of agricultural yield or yield reduction, both in $\mathrm{kg}$ dry matter per ha. For specific applications, for instance when yield reduction because of drought which is induced by pumping up of groundwater by drinking water companies is to be compensated financially, it is more interesting to know the economic effect in financial terms. Fig. 11 gives an example for grassland showing also the effect of differences in grassland management. In this case the potential yield is shown and expressed in $€$ per ha. This is calculated on the basis of the nutritive value and energy content of grass, depending on the moment within the growing season when the grass is cut or grazed. When grassland is only cut (mown) several times during the growing season the 30 -year average yield 
378 for all simulations is highest and when grassland is only used for grazing the agricultural production

379 potential will be lowest. In the Netherlands it is common that grassland is both cut and grazed within

380 one season. The intensity of cutting and grazing defines the production potential both in dry matter yield

381 as in financial result.

\section{Discussion}

384 The project Watervision Agriculture aims at a climate-robust instrument that can determine crop yield

385 effects as a result of drought, too wet or too saline conditions, based on process based models and an 386 economic assessment. This instrument can be used at field level and the meta-model allows an 387 application at regional level or national level showing long term effects or differences between years.

388 As shown in this paper with some examples the instrument can be applied for decision makers to show

389 the effects of climate scenarios or land use changes or changes in hydrology or combinations of these

390 effects. We have also shown the possibility to focus on the results for a specific crop or soil type and to

391 calculate effects in terms of kg dry matter or in $€$ per ha. With these different components of WaterVision

392 Agriculture we have made a toolbox for different applications as might be requested by the different end 393 users, based on methods that are well known within quantitative land evaluation.

395 For decisions on land use it is expected that decision makers will use both WaterVision Agriculture and

396 WaterVision Nature (Bartholomeus et al., 2018). This will enable them to take into account what will 
397 be the effect of their plans for both agricultural land and nature areas. Combining both instruments will

398 provide insight in possibilities for optimal regional water management.

399

400 In the autumn of 2018 WaterVision Agriculture will be released for use by anyone who may want to

401 apply the instrument. We expect many suggestions and requests for additions from all these users, and

402 implementing further aspects based on these requests will enable us to improve the methods even further

403 in order to enhance use for better decisions on sustainable soil and water management in current and

404 future climate.

405 Acknowledgements

406 This project is financed by: STOWA (Applied Research of the Water Authorities), Ministry of

407 Infrastructure and Environment, ACSG (Advisory Commission for Damage related to Groundwater),

408 provinces Utrecht and Zuid-Holland, ZON (Zoetwatervoorziening Oost-Nederland), Drinking water

409 companies Vitens and Brabant Water, VEWIN, LTO and the Ministry of Economic Affairs (project KB-

410 24-002-008). The first author would like to thank prof. Johan Bouma for the lasting inspiration for using

411 quantitative land evaluation methods for a career in soil and water management that started in 1987.

412

413 


\section{References}

415 Bartholomeus, R. P., Witte, J. P. M., Van Bodegom, P. M., Van Dam, J. C., and Aerts, R., 2008. Critical

416 soil conditions for oxygen stress to plant roots: substituting the Feddes-function by a process-based 417 model, J Hydrol, 360, 147-165.

418

419 Bartholomeus, R. P., Witte, J.P.M., Van Bodegom, P.M., Van Dam, J.C., De Becker, P., and Aerts, R., 420 2012. Process-based proxy of oxygen stress surpasses indirect ones in predicting vegetation 421 characteristics. Ecohydrology, 5(6), 746-758. doi:10.1002/eco.261

422

423 Bartholomeus, R., Hack-ten Broeke, M., Heinen, M., Mulder, M., Kros, H., Ruijtenberg, R., Runhaar, 424 H. and Witte, F., 2018. WaterVision Agriculture and Nature. Landschap 35-1, 15-23 (in Dutch)

426 Bonfante, A., and Bouma, J., 2015. The role of soil series in quantitative land evaluation when 427 expressing effects of climate change and crop breeding on future land use. Geoderma 259: 187-195. 428 https://doi-org.ezproxy.library.wur.nl/10.1016/j.geoderma.2015.06.010

430 Bouma, J., 1996. In: Discussion of: D.G. Rossiter, A theoretical framework for land evaluation.

431 Geoderma, 72: 191-192. https://doi-org./10.1016/0016-7061(96)00029-8

433 Bouma, J., 2000. Land evaluation for landscape units. In: Sumner, M.E. (ed.), Handbook 434 of Soil Science. CRC, Boca Raton, pp. E393-E412. 
436 Bouma, J. and Van Lanen, H.A.J., 1987. Transfer functions and threshold values: from soil 437 characteristics to land qualities. In: Quantified Land Evaluation. Proc. of a workshop by ISSS/SSSA. 438 ITC-publication 6, pp. 106-111.

439

440 Bouma, J. and Bregt, A.K. (eds.), 1989. Land qualities in space and time. Pudoc, Wageningen.

442 Bouma, J. and Wösten, J.H.M., 2016. How to characterize 'good' and 'greening' in the EU Common 443 Agricultural Policy (CAP): the case of clay soils in the Netherlands. Soil Use and Management 32: 546444 552. https://doi-org/10.1111/sum.12289 445

446 Breiman, L., 2001. Random Forests, Machine Learning 45(1), 5-32.

448 De Wit, A., Boogaard, H., Fumagalli, D., Janssen, S., Knapen, R., Van Kraalingen, D., Supit, I., Van 449 der Wijngaart, R. and Van Diepen, K., 2018. 25 years of the WOFOST cropping systems model. 450 Agricultural systems (in press). https://doi.org/10.1016/j.agsy.2018.06.018

452 FAO, 1976. A framework for land evaluation. FAO, Rome. 72 pp.

454 Feddes, R.A., Kowalik, P.J., Zaradny, H., 1978. Simulation of field water use and crop yield. 455 Wageningen, PUDOC. Simulation Monographs. 
457 Hack-ten Broeke, M.J.D., Kabat, P and Van Lanen, H.A.J., 1989. Temporal variability of workability,

458 and planting and emergence dates in relation to crop yield for two contrasting soils in the Netherlands.

459 In: Bouma, J. and Bregt, A.K. (eds.), 1989. Land qualities in space and time. Pudoc, Wageningen, pp. $460 \quad 177-180$.

461

462 Hack-ten Broeke, M.J.D., Kroes, J.G., Bartholomeus, R.P., Van Dam, J.C., De Wit, A.J.W., Supit, I., 463 Walvoort, D.J.J., Van Bakel, P.J.T. and Ruijtenberg, R., 2016. Quantification of the impact of hydrology 464 on agricultural production as a result of too dry, too wet or too saline conditions. SOIL 2: 391-402. 465

466 Heinen, M., Mulder, M., Walvoort, D., Bartholomeus, R., Stofberg, S., Hack-ten Broeke, M., 2017. 467 Praktijktoets Waterwijzer Landbouw in pilotgebieden De Raam en Vecht, Amersfoort, STOWA-rapport

468

469

470

471 input variables. Commun. Statist.-Simula. Computa. 11, 311-334.

472

473 IUSS Working Group WRB, 2015. World Reference Base for Soil Resources 2014, update 2015

474 International soil classification system for naming soils and creating legends for soil maps. World Soil 475 Resources Reports No. 106. FAO, Rome.

476

477

478 479

2017-44 (in Dutch)

Iman, R. L. and Conover, W. J., 1982. A distribution-free approach to inducing rank correlation among

KNMI, 2014. KNMI'14: Climate Change scenarios for the 21st Century - A Netherlands perspective. Scientific Report WR2014-01, KNMI, De Bilt, the Netherlands (www.climatescenarios.nl) 
480 Knotters, M., Bartholomeus, R., Hack-ten Broeke, M., Hendriks, R., Holshof, G.J., Hoving, I., Kroes,

481 J., Mulder, M. and Walvoort, D., 2017. Waterwijzer Landbouw fase 3: naar een operationeel systeem 482 voor gras en maïs. Amersfoort, the Netherlands. STOWA-report 2017-07 (in Dutch)

483

484 Kroes, J. G., Van Dam, J.C., Bartholomeus, R.P., Groenendijk, P., Heinen, M., Hendriks, R.F.A., 485 Mulder, H.M., Supit, I and Van Walsum, P.E.V., 2017. SWAP version 4. Theory description and user 486 manual. Site www.swap.alterra.nl. Wageningen, the Netherlands. Wageningen Environmental Research 487 Report 2780.

488

489 Kroes, J., Bartholomeus, R., Van Dam, J., Hack-ten Broeke, M., Supit, I., Hendriks, R.., De Wit, A., 490 Van der Bolt, F., Walvoort, D., Hoving, I., Van Bakel, J., 2015. Waterwijzer Landbouw, fase 2. 491 Modellering van het bodem-water-plantsysteem met het gekoppelde instrumentarium SWAP492 WOFOST. STOWA, Amersfoort, Rapport 2015-16 (in Dutch).

493

494 Maas, E. V. and Hoffman, G. J., 1977. Crop salt tolerance - current assessment. J. Irrigation and 495 Drainage Division ASCE 103 (IRI): 115-134. Proceeding Paper 12993.

496

497 Rossiter, D.G, 1996. A theoretical framework for land evaluation. Geoderma 72: 165-190.

498 https://doi.org/10.1016/0016-7061(96)00031-6

499 
500 Schils, R.L.M., De Haan, M.H.A., Hemmer, J.G.A., Van den Pol-van Dasselaar, A., de Boer, J.A.,

501 Evers, A.G., Holshof, G., Van Middelkoop J.C. and Zom, R.L.G., 2007. DairyWise, A Whole-Farm

502 Dairy Model. Journal of Dairy Science 90: 5334 -5346. https://doi.org/10.3168/jds.2006-842

503

504 Sonneveld, M.P.W., Hack-ten Broeke, M.J.D., Van Diepen, C.A. and Boogaard H.L., 2010. Thirty years

505 of systematic land evaluation in the Netherlands. Geoderma 156: 84-92.

506 https://doi-org/10.1016/j.geoderma.2010.02.023

507

508 Van Dam, J. C., Groenendijk, P., Hendriks, R. F. A. and Kroes J. G., 2008. Advances of modeling water

509 flow in variably saturated soils with SWAP. Vadose Zone J., Vol.7, No.2.

510

511 Van Diepen, C.A., Wolf, J. and Van Keulen, H., 1989. WOFOST: a simulation model of crop

512 production. Soil Use and Management, 5:16-24.

513

514 Van Diepen, C.A., Van Keulen, H., Wolf, J. and Berkhout, J.A.A., 1991. Land Evaluation: From

515 Intuition to Quantification. in: Stewart, B.A. (Ed.), Advances In Soil Science. Springer, New York, pp.

$516 \quad 139-204$

517

518 Van Keulen, H. and Wolf J. (Eds), 1986. Modelling of agricultural production: weather, soils and crops.

519 Simulation Monographs, Pudoc Wageningen, the Netherlands.

520 
521 Van Lanen, H.A.J., Hack-ten Broeke, M.J.D., Bouma, J. and De Groot, W.J.M., 1992a. A mixed

522 qualitative/quantitative physical land evaluation methodology. Geoderma, 55: 37-54.

524 Van Lanen, H.A.J., Van Diepen, C.A., Reinds, G.J. and De Koning, G.H.J., 1992b. A comparison of

525 qualitative and quantitative physical land evaluations, using an assessment of the potential for sugar beet

526 growth in the European Community. Soil Use Manage., 8: 80-89.

528 Van Lanen, H.A.J., Van Diepen, C.A., Reinds, G.J., De Koning, G.H.J., Bulens, J.D. and Bregt, A.K.,

529 1992c. Physical land evaluation methods and GIS to explore the crop growth potential and its effects

530 within the European Communities. Agricultural Systems 39: 307-328.

532 Van Lanen, H.A.J., Van Diepen, C.A., Reinds, G.J. and De Koning, G.H.J., 1992c. A comparison of

533 qualitative and quantitative physical land evaluations, using an assessment of the potential for sugar beet

534 growth in the European Community. Soil Use Manage., 8: 80-89.

535

536 Wösten, H., De Vries, F., Hoogland, T., Massop, H., Veldhuizen, A., Vroon, H., Wesseling, J., Heijkers,

537 J., Bolman, A., 2013. BOFEK2012, de nieuwe bodemfysische schematisatie van Nederland. Alterra,

538 Wageningen. Rapport 2387 (in Dutch). 


\section{Figure captions}

Figure 1. Transport processes and modelling domain of SWAP; Figure also used by Hack-ten Broeke et al. (2016).

Figure $2 \mathrm{a}$. Transpiration reduction factor $\alpha_{\mathrm{s}}$ as function of soil water pressure head and $\mathrm{b}$. Transpiration reduction factor $\alpha_{\mathrm{s}}$ as function of soil water electrical conductivity.

Figure 3. Schematization of the oxygen module used to simulate daily respiration reduction. The model combines interacting physiological processes (i.e. root respiration and microbial respiration) and physical processes (i.e. macro-scale and micro-scale oxygen diffusion). Details of equations involved are given in Bartholomeus et al. (2008). Figure taken from Bartholomeus et al. (2012)

Figure 4. Flow chart of crop growth processes included in WOFOST

Figure 5. Location of two pilot regions in the Netherlands: De Raam and De Vecht

Figure 6. 30-year average relative yield for grassland (above) and silage maize (below) for pilot area De Raam as quantified with WaterVision Agriculture (WVA-table). The relative yield is given as a percentage of the potential yield. The total relative yield is shown on the left, the part of this yield as affected by drought stress only is shown in the middle and the relative yield as effected by water excess only (i.e. oxygen stress) is shown on the right

Figure 7. 30-year average relative yield and relative yields for the years 1996 and 1998 for grassland (above) and silage maize (below) for pilot area De Raam as quantified with WaterVision Agriculture (WVA-table).

Figure 8. 30-year average relative yield for grassland (above) and silage maize (below) for a region within pilot area De Vecht as quantified with WaterVision Agriculture (WVA-table). The relative yield is given as a percentage of the potential yield. The total relative yield is shown on the left, the part of this yield as affected by drought stress only is shown in the middle and the relative yield as effected by water excess only (i.e. oxygen stress) is shown on the right

Figure 9. Simulated changes in 30-year average relative yield for grassland (above) and silage maize (below) for a region within pilot area De Vecht as quantified with WaterVision Agriculture (WVA-table) as a result of either potential hydrological measures (left) or as a result of climate scenario WH (right). For grey areas no changes were found.

Figure 10. Boxplot of simulated yield reduction for potato grown on a Cambic Podzol with a wet (left) and dry (right) groundwater regime. Each boxplot shows yield reduction as a result of indirect effects (brown), oxygen stress (blue), drought stress (red) or too saline conditions in the root zone (yellow). Results are shown without irrigation (above) and with irrigation (below)

Figure 11. Boxplot of simulated financial yield (€/ha) for grassland with varying grassland management 


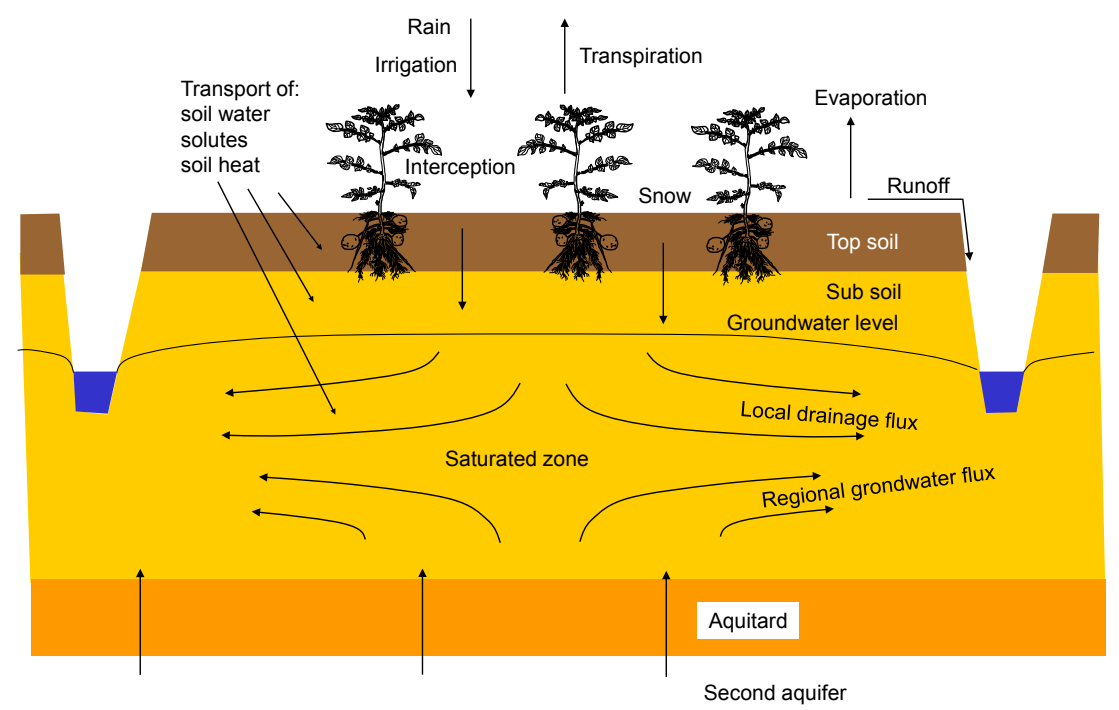

Figure 1. Transport processes and modelling domain of SWAP; Figure also used by Hack-ten Broeke et al. (2016). 


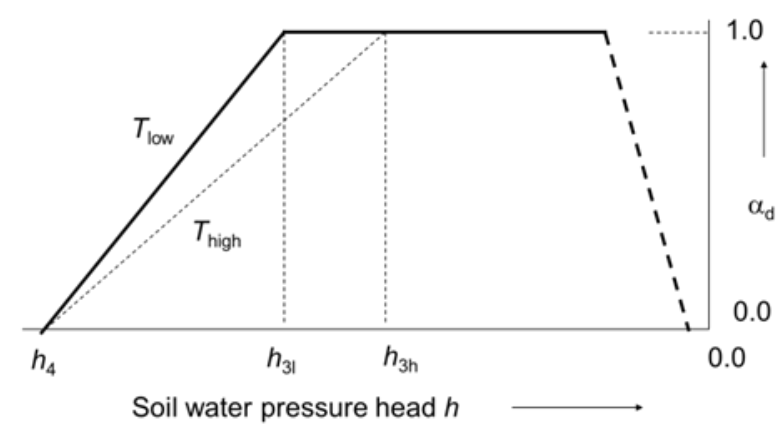

Figure 2a. Transpiration reduction factor $\mathrm{a}_{\mathrm{s}}$ as function of soil water pressure head.

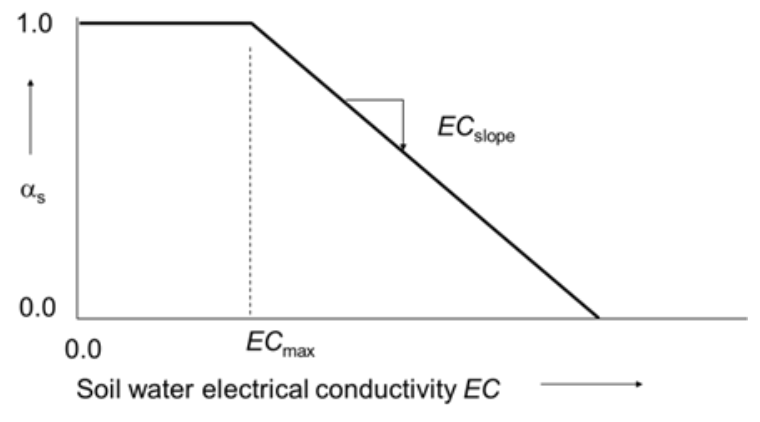

Figure 2b. Transpiration reduction factor $a_{s}$ as function of soil water electrical conductivity. 


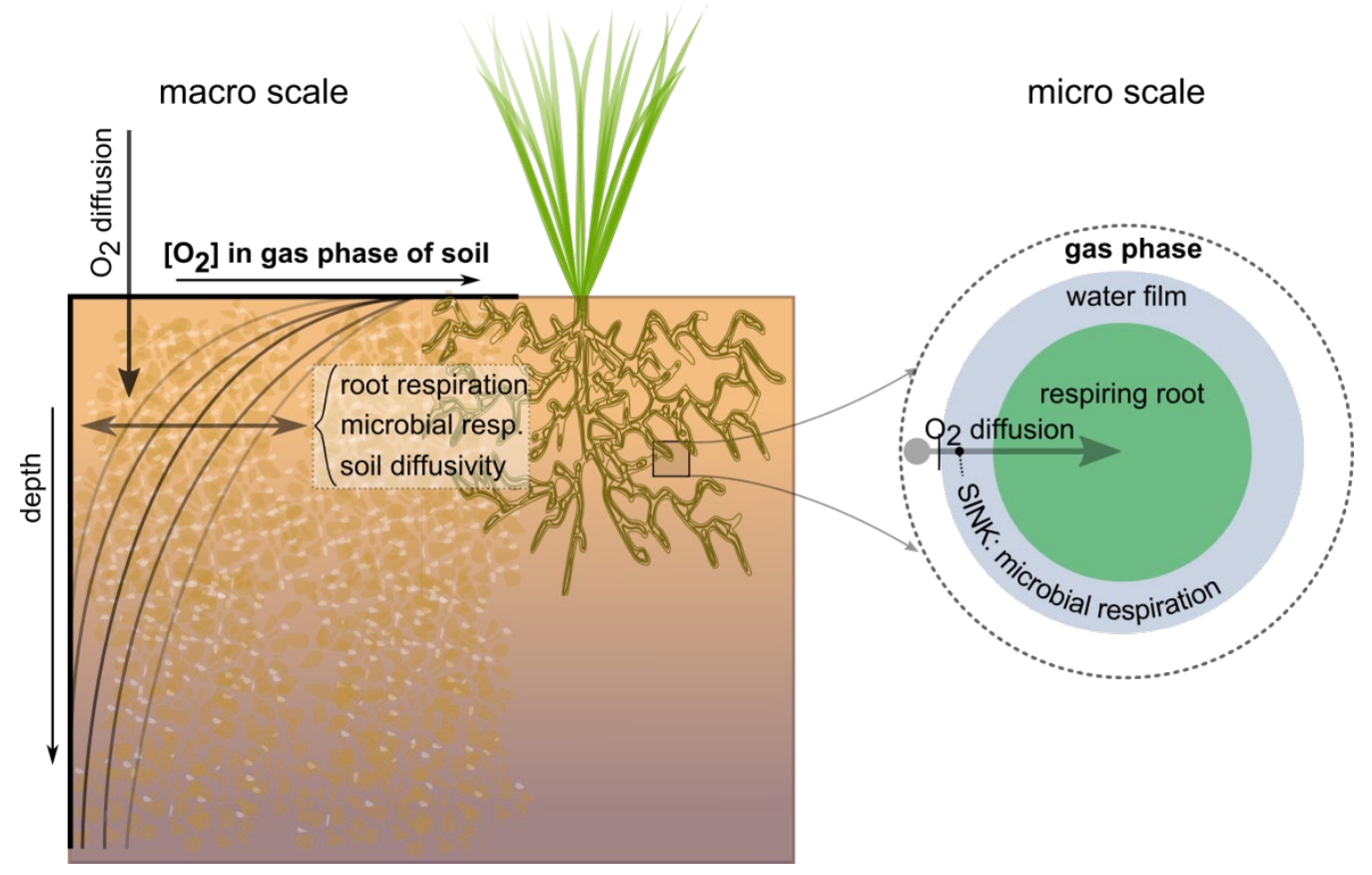

Figure 3. Schematization of the oxygen module used to simulate daily respiration reduction. The model combines interacting physiological processes (i.e. root respiration and microbial respiration) and physical processes (i.e. macro-scale and micro-scale oxygen diffusion). Details of equations involved are given in Bartholomeus et al. (2008). Figure taken from Bartholomeus et al. (2012) 


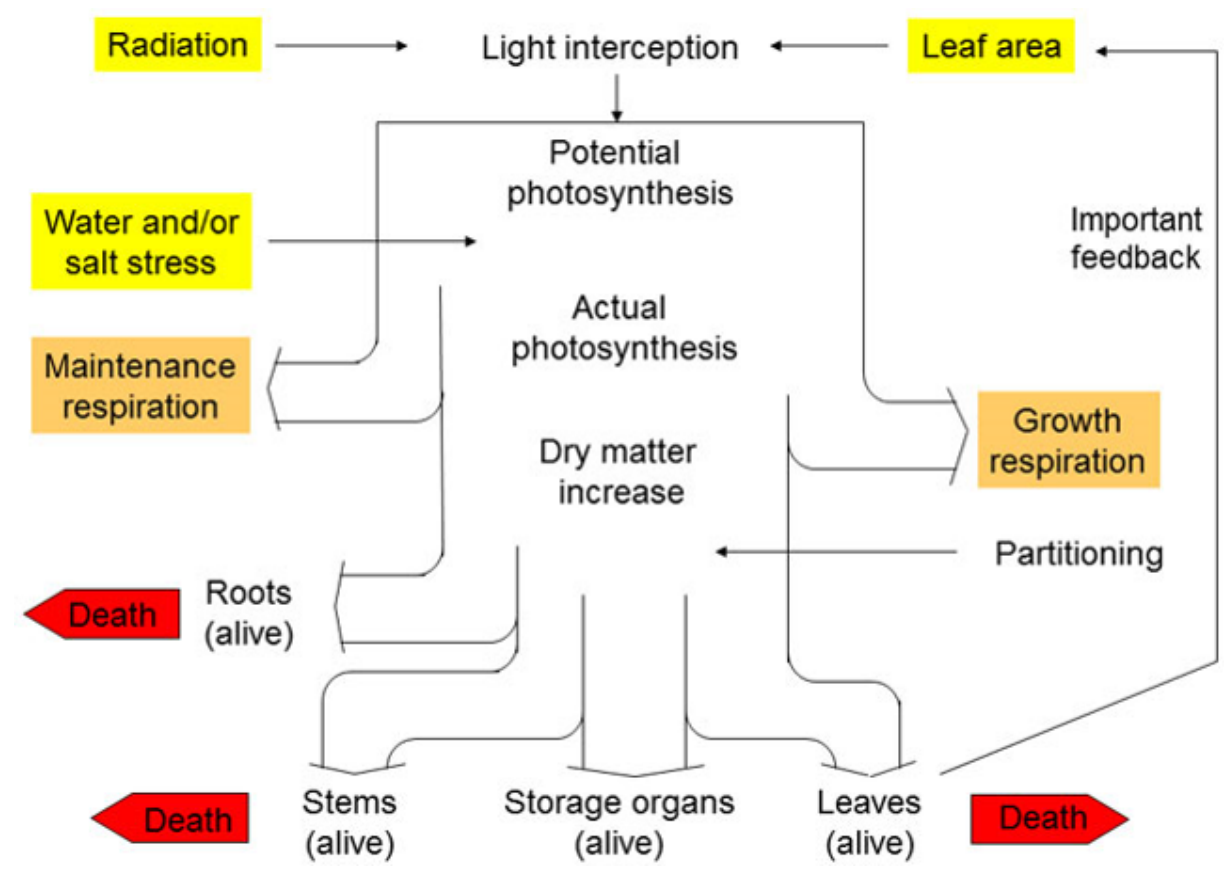

Figure 4. Flow chart of crop growth processes included in WOFOST 


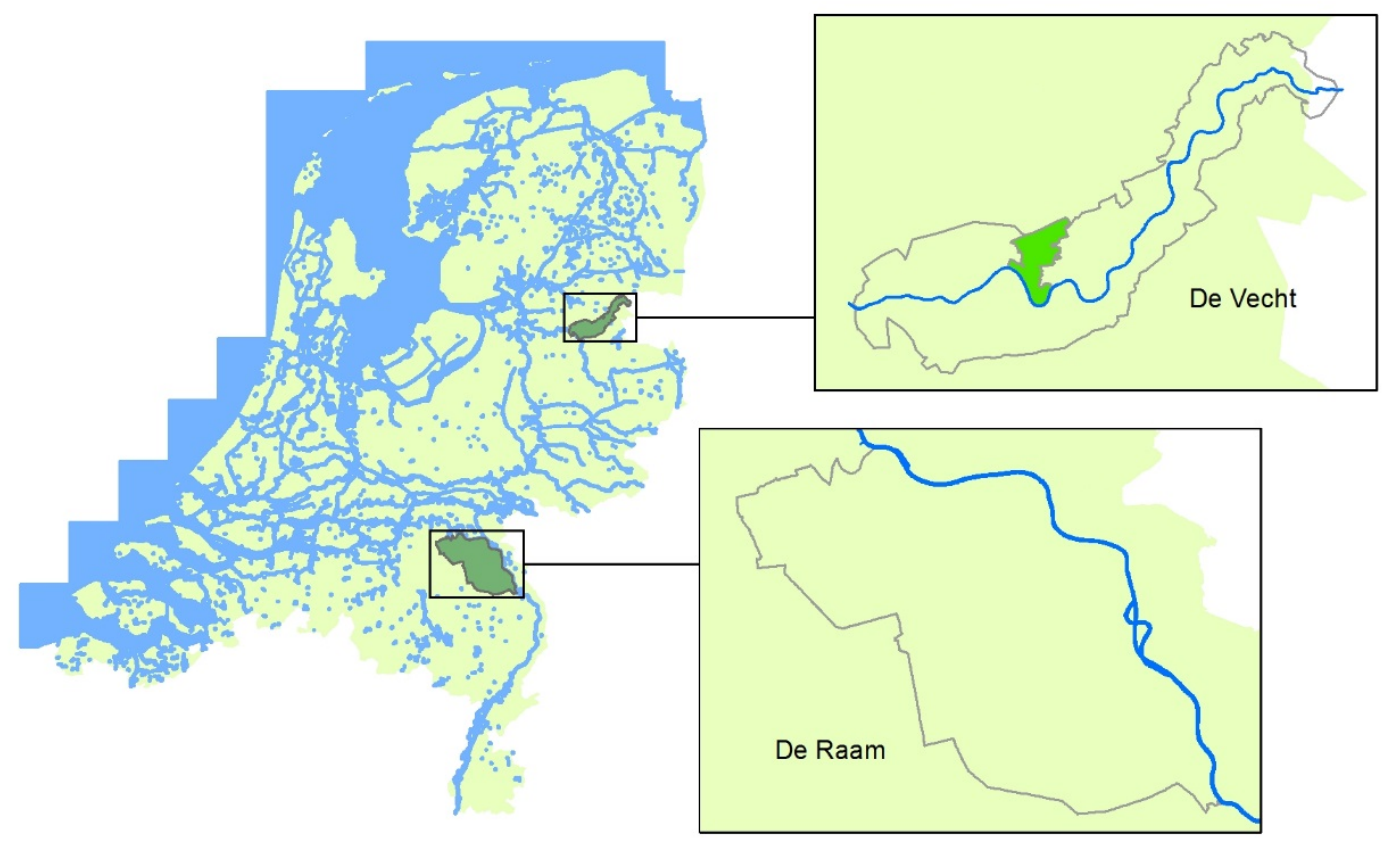

540

Figure 5. Location of two pilot regions in the Netherlands: De Raam and De Vecht 

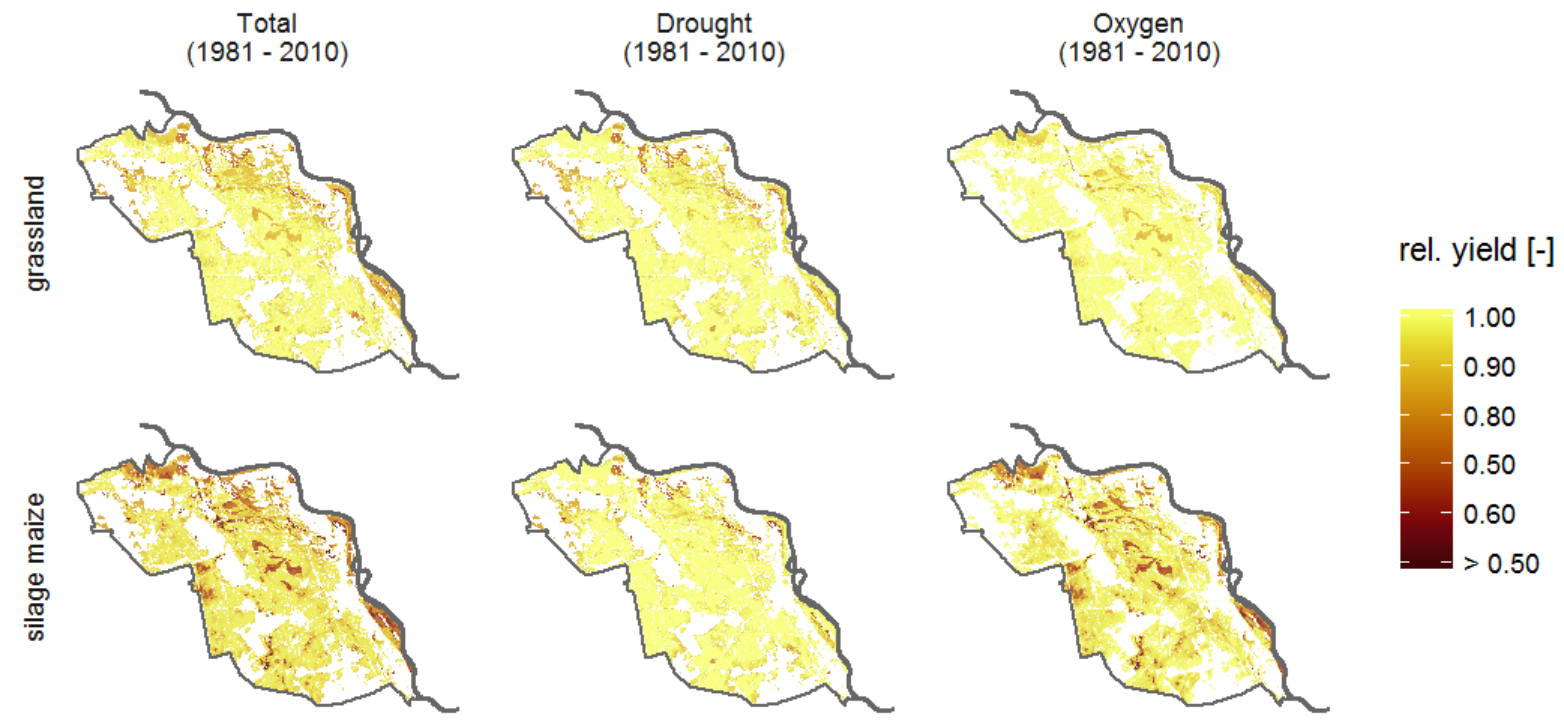

Figure 6. 30-year average relative yield for grassland (above) and silage maize (below) for pilot area De Raam as quantified with WaterVision Agriculture (WVA-table). The relative yield is given as a percentage of the potential yield. The total relative yield is shown on the left, the part of this yield as affected by drought stress only is shown in the middle and the relative yield as effected by water excess only (i.e. oxygen stress) is shown on the right 

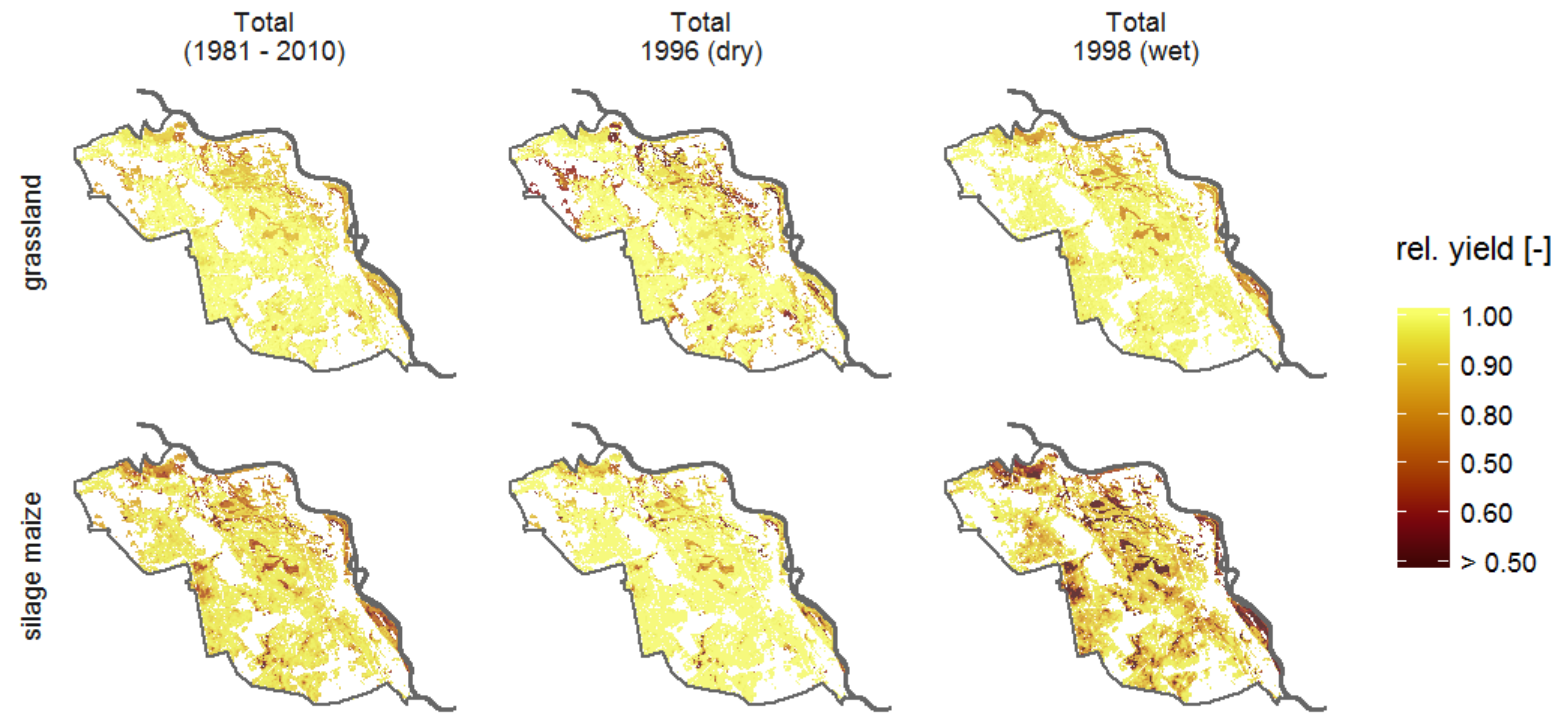

Figure 7. 30-year average relative yield and relative yields for the years 1996 and 1998 for grassland (above) and silage maize (below) for pilot area De Raam as quantified with WaterVision Agriculture (WVA-table). 

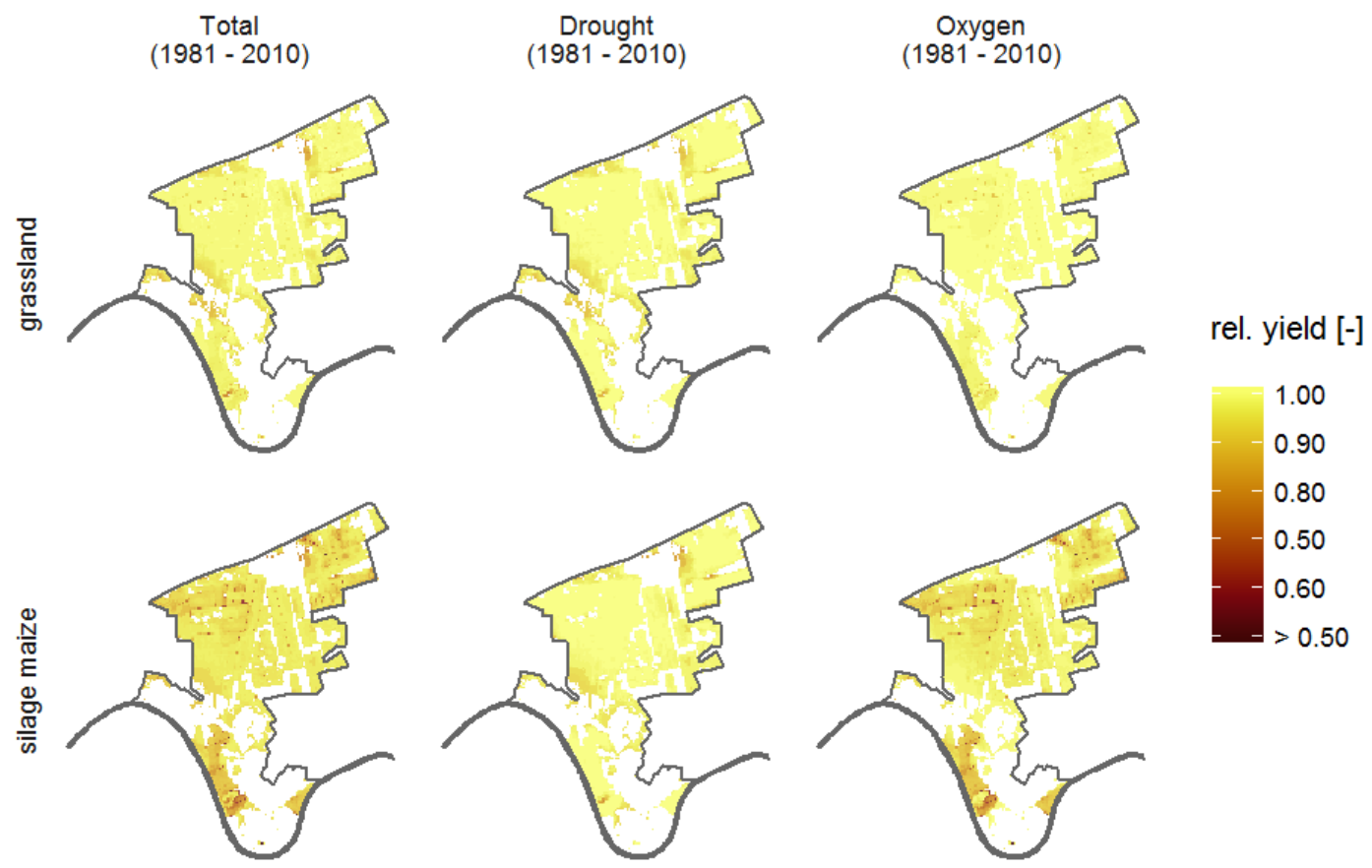

Figure 8. 30-year average relative yield for grassland (above) and silage maize (below) for a region within pilot area De Vecht as quantified with WaterVision Agriculture (WVA-table). The relative yield is given as a percentage of the potential yield. The total relative yield is shown on the left, the part of this yield as affected by drought stress only is shown in the middle and the relative yield as effected by water excess only (i.e. oxygen stress) is shown on the right 

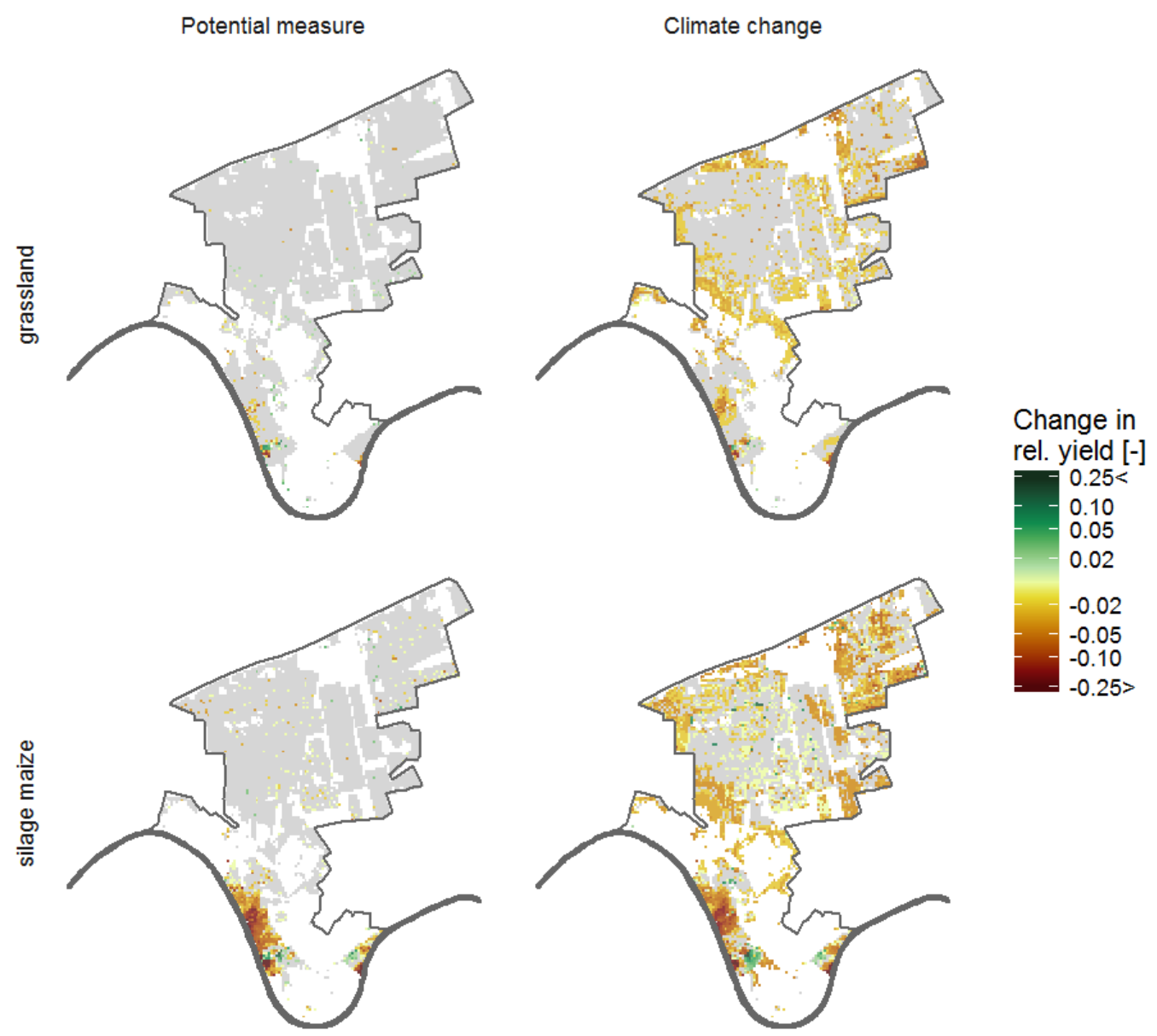

Figure 9. Simulated changes in 30-year average relative yield for grassland (above) and silage maize (below) for a region within pilot area De Vecht as quantified with WaterVision Agriculture (WVA-table) as a result of either potential hydrological measures (left) or as a result of climate scenario WH (right). For grey areas no changes were found. 


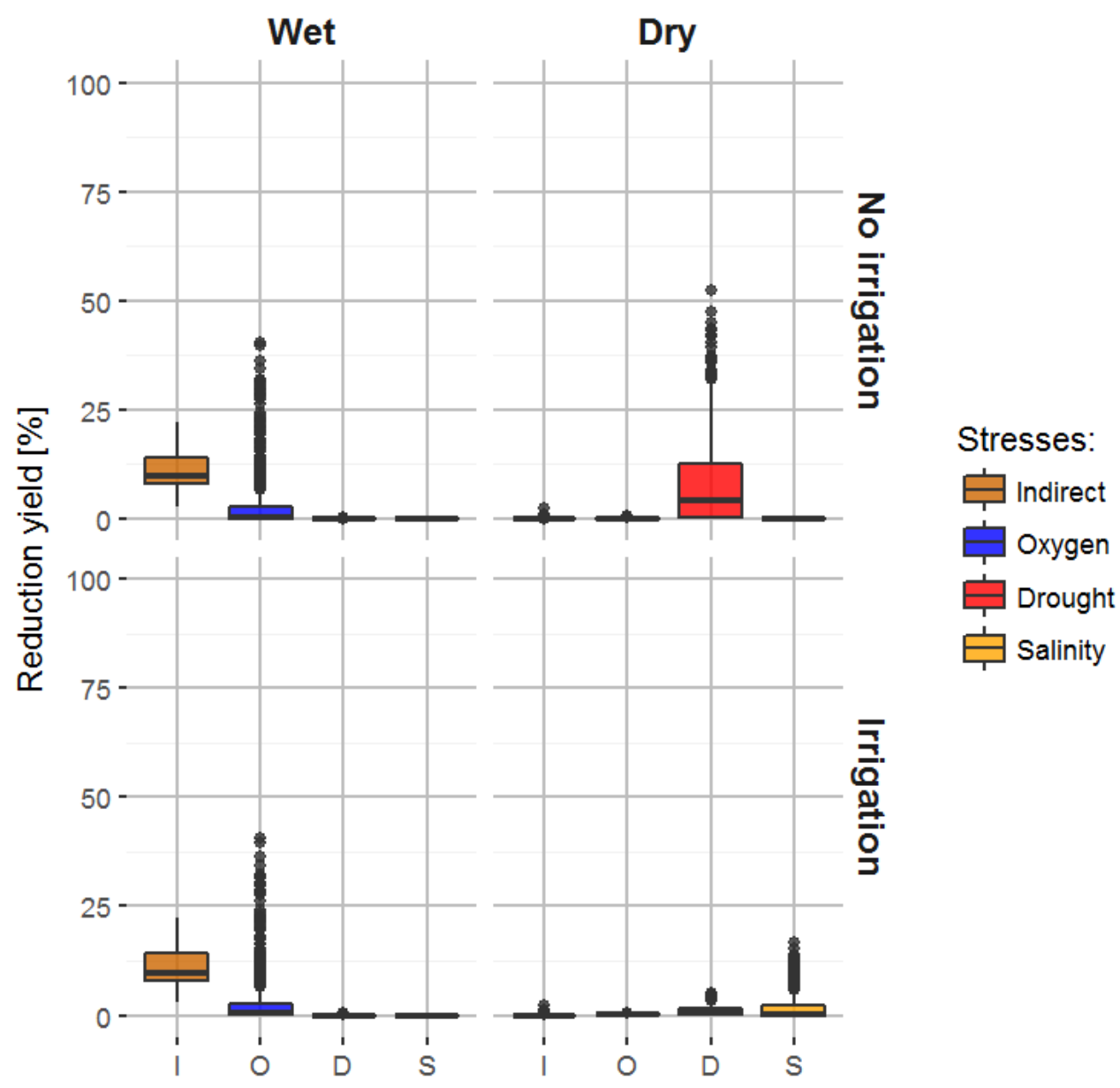

Figure 10. Boxplot of simulated yield reduction for potato grown on a Cambic Podzol with a wet (left) and dry (right) groundwater regime. Each boxplot shows yield reduction as a result of indirect effects (brown), oxygen stress (blue), drought stress (red) or too saline conditions in the root zone (yellow). Results are shown without irrigation (above) and with irrigation (below) 


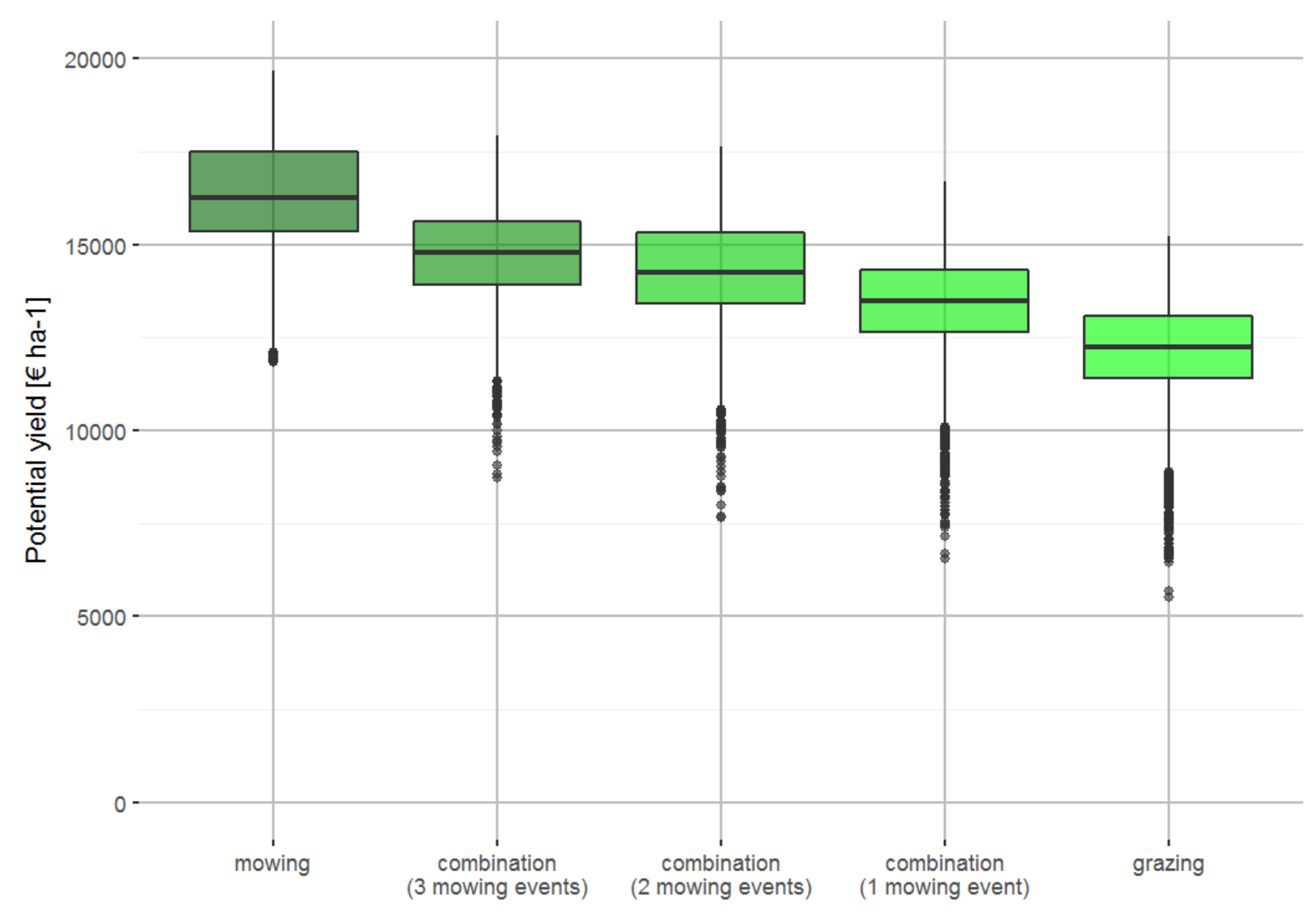

Figure 11. Boxplot of simulated financial yield $(€ / \mathrm{ha})$ for grassland with varying grassland management 